\section{Difficult extubation after large tongue swelling in intensive care unit}

Sir,

A 65-year-old female patient presented with respiratory distress due to left ventricular failure. The patient was intubated by the attending doctor in view of hypoxia. During laryngoscopy and intubation, the posterior pharyngeal wall was lacerated. After placing the endotracheal tube, the posterior pharynx was packed to control the bleeding. On the second day of ventilation, the pack was removed gently; however the patient developed a large tongue swelling [Figure 1]. Even though patient's hemodynamics and oxygenation parameters were stabilized, extubation was therefore not attempted. Pieces of soft gauze were wrapped around the tongue to protect it from teeth bite. Tongue swelling gradually subsided permitting extubation on day 4 . Subsequently, the patient could maintain airway patency.

Tongue edema is mainly documented as a consequence of vascular compromise, lymphatic drainage obstruction, thromboembolism of lingual artery and compression due to hard bite block or in other situations such as a tight throat pack. ${ }^{[1]}$ Other mechanisms of tongue swelling are trauma, allergy, infection and massive post-operative fluid loading. ${ }^{[2]}$ In the present case, tight throat packing at the base of tongue in the posterior pharynx might have compromised lingual venous drainage leading to edema. Massive lingual swelling contributes to airway compromise. It may worsen after tracheal tube removal, leading to partial or complete airway obstruction. ${ }^{[3]}$ Tracheal reintubation may prove difficult or impossible. ${ }^{[4]}$

Monish S. Raut, Arun Maheshwari Department of Cardiac Anesthesia, Dharam Vira Heart Center, Sir Ganga Ram Hospital, New Delhi, India

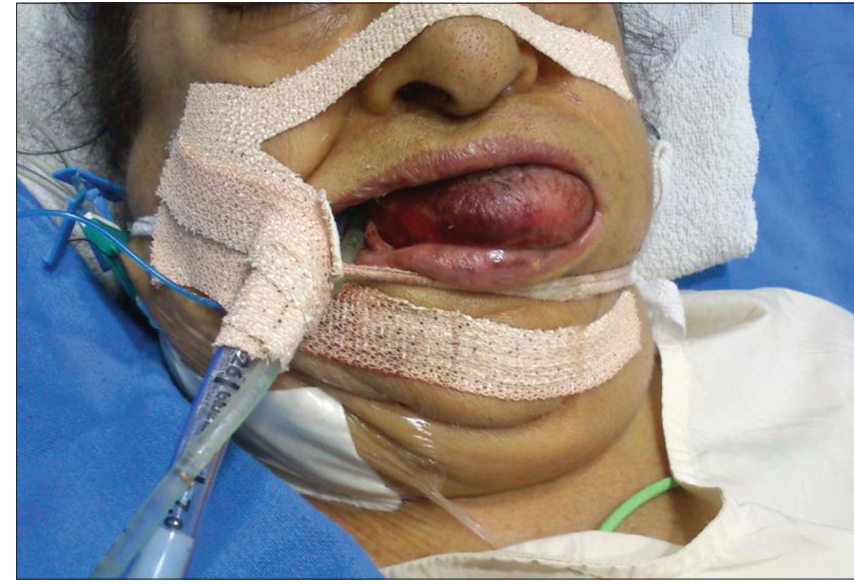

Figure I: Post intubation large tongue swelling

$$
\begin{array}{r}
\text { Correspondence: } \\
\text { Dr. Monish S. Raut, Department of Cardiac } \\
\text { Anesthesia, Dharam Vira Heart Center, } \\
\text { Sir Ganga Ram Hospital, } \\
\text { Old Rajinder Nagar, } \\
\text { New Delhi - } 110 \text { 060, India. } \\
\text { E-mail: drmonishraut @ gmail.com }
\end{array}
$$

\section{References}

1. Kawaguchi M, Sakamoto T, Ohnishi H, Karasawa J. Pharyngeal packs can cause massive swelling of the tongue after neurosurgical procedures. Anesthesiology 1995;83:434-5.

2. Grigsby EJ, Lennon RL, Didier EP, Liu TL. Massive tongue swelling after uncomplicated general anaesthesia. Can J Anaesth 1990;37:825-6.

3. Lam AM, Vavilala MS. Macroglossia: Compartment syndrome of the tongue? Anesthesiology 2000;92:1832-5.

4. Twigg S, Brown JM, Williams R. Swelling and cyanosis of the tongue associated with use of a laryngeal mask airway. Anaesth Intensive Care 2000;28:449-50

\begin{tabular}{|l|l|}
\hline \multicolumn{2}{|c|}{ Access this article online } \\
\hline Quick Response Code: & Website: \\
\hline & www.ijccm.org \\
\cline { 2 - 3 } & Dol: 10.4103/0972-5229.130583 \\
\hline
\end{tabular}

